\title{
Discussão pós implantação das possíveis contribuições da ergonomia no projeto de automatização de linhas de produção
}

\section{Discussion after implementation of possible ergonomics contributions in production lines automation project}

José Adriano Canton ${ }^{1}$ - Univ. Federal de São Carlos - Dep. de Pós-Graduação de Engenharia de Produção Andrea Regina Martins Fontes ${ }^{2}$ - Univ. Federal de São Carlos

Isaías Torres ${ }^{3}$ - Univ. Federal de São Carlos

RESUM0 Este artigo aborda a temática de concepção de espaços de trabalho a partir da perspectiva da Ergonomia Situada. O objetivo foi o de refletir o papel da Ergonomia no projeto de situações produtivas a fim de antecipar e mitigar o aparecimento de novos constrangimentos. Para o desenvolvimento deste trabalho foi utilizado um estudo de caso em uma indústria de embalagens, na qual foi implantada uma linha automatizada em substituição a demandas de afastamentos no trabalho manual anteriormente realizado. O presente artigo baseou-se nos resultados da Análise Ergonômica do Trabalho da situação implantada e da análise à posteriori do processo de projeto da referida melhoria. Analisou-se que a solução adotada não permite margem de manobra para lidar com as variações inerentes ao processo, sendo necessárias constantes intervenções de operadores para a liberação e continuação dos trabalhos da linha. Evidenciou-se que a solução implantada não teve a participação de atores importantes como os operadores e o pessoal da manutenção, direcionando um olhar tecnicista que buscou eliminar o fator humano. Concluiu-se que a Ergonomia integrada no desenvolvimento do projeto favorece a construção coletiva da análise do trabalho e consequentemente a elaboração de soluções mais eficazes.

Palavras-chave Ergonomia da Atividade. Análise Ergonômica do Trabalho. Inovação tecnológica. Automatização. Embalagem de polpa moldada. Processo social de projeto.

ABSTRACT This paper addresses the issue of work spaces designed based on Activity-Centered Ergonomics. The aim was to reflect on the role of Ergonomics in the design of productive situations in order to anticipate and mitigate the emergence of new constraints. This study was developed using a case study from the packaging industry, where an automated line was implemented to mitigate the injuries suffered as result of the manual system. This article was based on the results of an Ergonomic Work Analysis of the solution implemented, and the subsequent analysis of this design process. It was found that the adopted solution does not have enough leeway for dealing with variations inherent to the process, requiring constant interventions in the operation, by the operators in order to free the line to continue work. It was evident that the adopted solution did not involve the participation of important agents such as the operators and the maintenance crew, giving the project a technical vision that was concerned with eliminating the human factor. The conclusion of this study was that the Ergonomics integrated into the project development favors the collective construction of analysis of the research, and consequently, the development of more effective solutions.

Keywords Ergonomics of Activity. Ergonomic Work Analysis. Technologic innovation. Automation. Molded pulp packaging. Social process of design.

1. Rodovia João leme dos Santos, km 110, s/n, Sorocaba, São Paulo, CEP: 18052-780, adriano.canton@sanovo.com.br

2.andrea@dep.ufscar.br

3. isaias@ufscar.br

CANTON, J. A.; FONTES, A. R. M.; TORRES, I. Discussão pós implantação das possíveis contribuições da ergonomia no projeto de automatização de linhas de produção. GEPROS. Gestão da Produção, Operações e Sistemas, Bauru, Ano 11, nº 4, out-dez/2016, p. $267-283$.

DOI: 10.15675/gepros.v11i4.1585 


\section{INTRODUÇÃO}

Para que as empresas se perpetuem no mercado, diante de um cenário de constantes alterações, é necessário que elas, assim como um organismo vivo, se adaptem a esse novo ambiente e busquem recursos que proporcionem essa adaptação de forma rápida (MORGAN, 2006).

Com normas cada vez mais rígidas como as Normas Regulamentadoras NR12 e NR17 (BRASIL, 2009), que estabelecem as condições de trabalho, incluindo aspectos relacionados a atividade dos trabalhadores, aos equipamentos e recursos disponíveis para a execução das atividades, e às condições ambientais do posto de trabalho e, também, à organização do trabalho, fazem com que as empresas invistam em melhorias nos postos de trabalho.

Quando se pensa em melhorias ergonômicas do espaço de trabalho, pensa-se logo em automatizar as operações envolvidas no processo. Porém quando se decide pela implantação de novas tecnologias em um determinado posto de trabalho é de suma importância tomar os cuidados para que nessa transformação não se cometa o equívoco de acreditar que o simples fato de alterar uma atividade, antes de ação puramente manual, por uma nova tecnologia que visa o automatismo dessa tarefa, que os riscos ergonômicos serão eliminados. Devido a falta de detalhamento da atividade que se pretende automatizar, agravado pelo não envolvimento de todos os atores que, de uma forma ou de outra, serão afetados por essa mudança, riscos importantes podem surgir após a implantação da nova tecnologia (ABRAHÃO, 2000).

O uso da Ergonomia nos projetos de concepção pode colaborar, significativamente, com o fornecimento de orientações gerais e específicas como normas e parâmetros ergonômicos (LIMA; DUARTE, 2014; BRAATZ, 2015). O desafio é fazer com que a Ergonomia da atividade atue antes do detalhamento do projeto, ainda na fase de definições e conceitos do projeto porque as alterações nessa fase não são tão complexas de se realizar e com um custo menor, comparando com os custos de adequações em fases mais avançadas do projeto (LIMA; DUARTE, 2014; BRAATZ, 2015).

Conhecer a realidade do posto de trabalho onde se pretende melhorar a forma de execuçao das tarefas é fator preponderante para que o projeto tenha êxito, porque isso contribui para a identificação de possíveis constrangimentos e o uso de recursos inadequados que podem ser propostos durante a concepção da nova instalação, antecipando problemas operacionais (RODRIGUES, 2012).

Considerando a importância deste tema, esta pesquisa foi desenvolvida a partir do viés da Ergonomia Situada, onde se pretendeu discutir o impacto de novas tecnologias no trabalho dos operadores. Para isso foram elencados o tema de projeto de situações produtivas, inovação e o papel da Ergonomia nesse processo. Para fazer essa reflexão foi selecionada uma empresa que produz embalagens na qual foi substituída uma linha manual por semiautomática.

O recorte de análise foi o processo de produção de bandeja de polpa moldada para o acondicionamento e transporte de maçãs. Dentro deste recorte foram inseridas as tarefas do processo de acondicionamento e paletização desse produto e como estas influenciavam na saúde e na produtividade dos trabalhadores.

Pretendeu-se buscar na literatura estudos que mostrassem a interação da Ergonomia na análise e caracterização das atividades bem como o seu papel de estabelecer a participação coletiva dos atores envolvidos no processo de melhoria das condições reais de trabalho. 


\section{REFERENCIAL TEÓRICO}

A maioria dos projetos de engenharia tradicionais, de concepção de espaço de trabalho, adota uma abordagem descendente, ou top-down (LIMA; DUARTE, 2014). O que caracteriza esse modelo é quanto a forma que os requisitos do projeto são levantados. A alta administração é quem define os requisitos limitantes do projeto como os objetivos e os recursos financeiros que serão destinados para o empreendimento. A partir dessas informações são selecionadas as opções técnicas disponíveis no mercado, que atendam esses requisitos (LIMA; DUARTE, 2014). O projeto, então, se desenvolve com recursos restritos, disponibilizados pela alta administração, com uma visão limitada quanto a complexidade do trabalho, objeto do investimento. Os requisitos iniciais não levam em consideração as necessidades dos trabalhadores que desempenharão as suas funções nesse espaço. É na fase final do projeto, na sua implantação, que surgem as discussões sobre a interface do usuário e a máquina (LIMA; DUARTE, 2014). Porém quanto mais próximo das etapas finais do projeto maior será o volume de recursos consumidos tornando mais dispendiosa qualquer alteração para a correção do projeto (ROLDÃO, 2004).

Fazer o levantamento de todas as informações relevantes para o projeto nas fases iniciais do seu desenvolvimento, na concepção e no planejamento, é uma tarefa que demanda tempo mas reduz o consumo de recurso extra para a correção de desvios na etapa de implementação do projeto (ROLDÃO, 2004).

O uso da abordagem ascendente, bottom-up, que leva em consideração as atividades de trabalho dos usuários, proporciona informações que auxiliam na escolha da melhor alternativa técnica para o posto de trabalho objeto do projeto (LIMA; DUARTE, 2014). O uso dessa abordagem nos momentos finais do desenvolvimento do projeto não traz grandes benefícios, pois as mudanças nessa etapa do projeto só incorrerão em maiores despesas. Lima e Duarte (2014), afirmam que a abordagem ascendente, quando aplicada nos momentos iniciais do desenvolvimento do projeto provoca uma maior reflexão por parte dos gestores do projeto, promovendo uma antecipação e consequente redução quanto às incertezas a respeito da eficácia $\mathrm{e}$ funcionamento futuro do projeto.

A Figura 1 ilustra como o uso da abordagem ascendente, bottom-up, complementando a abordagem descendente, top-down, aplicada nos momentos iniciais do desenvolvimento do projeto pode fornecer uma maior margem de manobra para mudanças necessárias com o intuito de atender as necessidades do posto de trabalho. Essa combinação das duas abordagens possibilita a antecipação e consequente redução das incertezas quanto à eficácia do funcionamento futuro do projeto (LIMA; DUARTE, 2014). 
Figura 1 - Uso da abordagem ascendente.

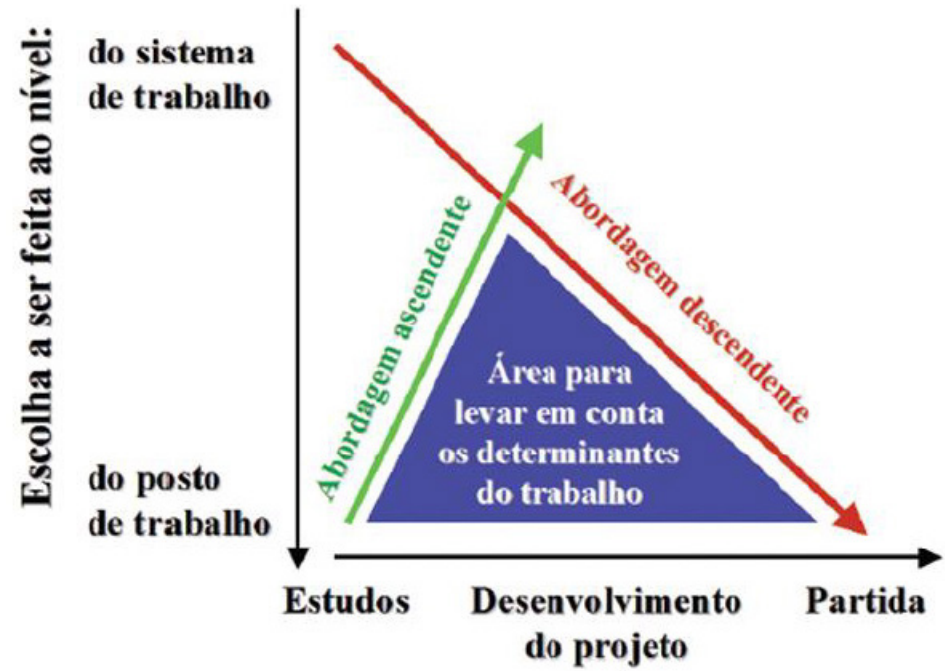

Fonte: Lima e Duarte, 2014 apud Maline, 1994.

Quanto maior o estudo e aprofundamento das alternativas de concepção de projetos nas fases iniciais maior será a influência no resultado do projeto (RODRIGUES, 2012). Postergar decisões e introduzir modificações nas fases mais avançadas trará maiores custos e menor flexibilidade na atuação dentro do projeto.

\subsection{0 uso da ergonomia em projetos de engenharia}

É raro encontrar nos modelos tradicionais de projetos de concepção o uso dos conceitos da Ergonomia durante o desenvolvimento do projeto, impossibilitando uma abordagem com foco na atividade, abordagem ascendente, o que poderia contribuir para um resultado mais assertivo no final desses projetos (RODRIGUES, 2012).

Rozenfeld et al. (2006), sugerem uma lista de participantes do processo de projeto e, entre esses participantes, estaria o "especialista". Para essa função seriam escolhidas pessoas de determinadas áreas funcionais da empresa ou uma consultoria, que tivesse um vasto conhecimento sobre as tecnologias empregadas no processo de fabricação ou sobre os métodos de trabalho. Segundo os autores, essa recomendação não deixa claro a utilização de um especialista em Ergonomia nos processos de desenvolvimento de projeto, mas pode-se interpretar que alguém que tenha um domínio sobre o processo de fabricação ou sobre os métodos de trabalho pode trazer informações importantes com relação às tarefas e ao trabalho praticado e, com isso, propor melhorias durante a elaboração do projeto. 
Braatz (2015), comenta que no campo da Ergonomia existem métodos, técnicas e ferramentas que podem auxiliar nos projetos de concepção de situações produtivas. As áreas de conhecimento relacionadas aos projetos do trabalho podem colaborar na incorporação da perspectiva da atividade (BRAATZ, 2015).

Importante ressaltar que não se trata de usar a Ergonomia em projetos de concepção como mais um elemento de especificação, mas usar os seus conceitos para promover uma discussão entre todas as áreas envolvidas no projeto (MENEGON, 1999). Como resultado dessa negociação haveria um conjunto de soluções que levasse em conta os aspectos evidenciados pela análise ergonômica (MENEGON, 1999). Segundo Menegon (1999), a ação ergonômica tem como objetivo ampliar os espaços de regulação na atividade dos projetistas e dos trabalhadores.

Este artigo pretendeu discutir a importância do emprego da Ergonomia nos projetos de engenharia não apenas para o cumprimento das exigências estabelecidas nas normas brasileiras como a Norma Regulamentadora número 17 (NR17) (LIMA; DUARTE, 2014), mas, a importância da sua participação, a partir de um espaço de construção coletiva, em projetos de concepção de espaços de trabalho seguindo os métodos tradicionais de desenvolvimento de projetos.

\subsection{Conceitos da ergonomia}

Em 1970 a Société d'Ergonomie de Langue Française (SELF) definiu a Ergonomia como sendo a adaptação do trabalho ao homem, ou seja, utilizar os conhecimentos científicos relativos ao homem para projetar ferramentas, máquinas e dispositivos que proporcionem conforto, segurança e eficácia na sua utilização (FALZON, 2007).

A International Ergonomics Association (IEA), em sua primeira definição da Ergonomia, também fez uma referência sobre a necessidade do estudo científico do homem em relação ao seus meios, métodos e ambientes de trabalho e, ainda, com a colaboração das diversas disciplinas científicas, para que seja possível adaptar ao homem os meios tecnológicos de produção e dos ambientes de trabalho (FALZON, 2007). A definição adotada no ano de 2000 pela IEA estabelece que a Ergonomia (ou Human Factors) é uma disciplina que visa a compreensão fundamental das interações entre os seres humanos e os outros componentes de um sistema, e a profissão que aplica princípios teóricos, dados e métodos com o objetivo de otimizar o bem-estar das pessoas e o desempenho global dos sistemas (IEA, 2015).

Segundo Falzon, (2007) a Ergonomia é uma disciplina que possui um duplo objetivo: um é voltado para as organizações e o seu desempenho, quanto a eficiência, produtividade, confiabilidade, qualidade e durabilidade; o outro objetivo está centrado nas pessoas, quanto a sua segurança, saúde, conforto, facilidade de uso, satisfação, interesse do trabalho e prazer. A prática da Ergonomia visa tornar as tarefas, produtos, empregos, organizações, meio ambiente e sistemas compatíveis com as capacidades e limites das pessoas levando em consideração, também, o resultado operacional (IEA, 2015). 


\section{- Distinção entre trabalho prescrito e real}

O trabalho prescrito pode ser entendido como sendo a tarefa que é imposta ao trabalhador pela empresa. A atividade de trabalho são as manobras feitas pelo trabalhador para se adaptar a situação real de trabalho (GUÉRIN et al., 2001). Guérin et al. (2001), comentam que essa diferença entre o prescrito e o real é a materialização das contradições existentes no ato do trabalho: "o que é pedido" e "o que a coisa pede" (GUÉRIN et al., 2001).

\section{- Conceito de variabilidade}

Guérin et al. (2001), dividem a variabilidade em dois aspectos: a variabilidade da empresa (variabilidade normal, que podem ser decorrentes das variações dos volumes de produção, da natureza da produção, dos tipos de produtos ou serviços oferecidos e as variações na qualidade da matéria prima; e a variabilidade incidental como, por exemplo, uma ferramenta que se quebra); e a variabilidade do indivíduo (diferenças existentes entre as pessoas, como: altura, idade, sexo, esforços, raciocínio). Abrahão (2000) diz que na variabilidade com relação a organização do trabalho devem ser incluídos os materiais, os equipamentos, os procedimentos e a gestão dos incidentes. No aspecto do trabalhador entram na variabilidade fatores inter e intra individuais (ABRAHÃO, 2000).

Fontes (2011), comenta que se as empresas conhecerem as suas variabilidades e suas causas forem determinadas, é possível reduzir a sua incidência através do desenvolvimento de projetos.

\section{- Conceito de modo operatório}

Guérin et al. (2001), descrevem o modo operatório como sendo a forma que um trabalhador se organiza para atingir os diversos objetivos. Ainda segundo os autores esses objetivos podem ser: metas fixadas pela empresa e objetivos pessoais fixados pelo próprio trabalhador visando a forma como ele realizará a sua atividade para atingir os objetivos da empresa. Para atingir os objetivos, o trabalhador elabora o seu modo operatório organizando suas ações através do tratamento das informações recebidas (GUÈRIN et al., 2001).

Fontes (2011), comenta que as atividades de projeto podem contribuir com o modo operatório propondo melhorias das situações existentes que visam alinhar os objetivos propostos pela empresa e os meios disponibilizados (FONTES, 2011).

\section{- Conceito de carga de trabalho}

A carga de trabalho, de acordo com Guérin et al. (2001), está relacionada com as modificações que o trabalhador promove na sua forma de trabalhar, ou seja, o modo operatório adotado. Este é definido através da composição dos objetivos exigidos, dos meios de trabalho disponíveis, dos resultados produzidos e do estado interno do trabalhador (GUÉRIN et al., 2001). Quanto menores forem as formas de se organizar para atingir objetivos, maior será a carga de trabalho. Ou seja, a carga de trabalho é inversamente proporcional à margem de manobra que o trabalhador dispõe para elaborar o seu modo operatório (GUÉRIN et al., 2001). 
Projetos de concepção podem contribuir com a redução da carga de trabalho modificando as situações existentes, visando o aumento da margem de manobra (FONTES, 2011).

\subsection{A Ergonomia e a inovação tecnológica}

Segundo Beguin e Duarte (2008), a inovação é um fator de competitividade entre as empresas. Com a entrada no mercado dos países emergentes, que possuem uma produtividade maior devido ao baixo custo do trabalho, é imperativo a busca por inovação tecnológica visando à produção, em alta velocidade, de produtos novos geradores de valor (BEGUIN; DUARTE, 2008).

Entre os aspectos levados em consideração na análise para a tomada da decisão de se investir em inovação de um posto de trabalho está a necessidade de se adequar o espaço de trabalho visando as condições de segurança e saúde dos usuários diretos desse espaço (BROBERG, 2008). Beguin e Duarte (2008), comentam que o tema da inovação traz à tona a discussão quanto a necessidade de uma requalificação das abordagens de concepção. Segundo os autores, o trabalho dos ergonomistas dentro desse tema é o de desenvolver caminhos que favoreçam o trabalho humano.

Algumas empresas necessitam alterar um modelo operacional baseado em um contexto social. E, dessa forma, entram na avaliação, para a tomada de decisão, aspectos que podem envolver a imagem da empresa perante a sociedade, questões legais devido a necessidade do cumprimento das legislações locais e, para aquelas empresas que almejam o mercado exterior, a necessidade do cumprimento de quesitos internacionais que envolvem os postos de trabalho da empresa, uma vez que muitos países exigem o cumprimento de diversas normas de segurança para aprovar um contrato de fornecimento (COCKELL; PERTICARRARI, 2005).

Outro fator, que vem contribuindo para o aumento do interesse das empresas em investir em melhorias nos postos de trabalho e, que pode ser usado como um aspecto econômico na avaliação do retorno do capital de um projeto de inovação, é a incidência de afastamentos devido a doenças ocupacionais, LER/DORT (que podem se transformar em futuros processos trabalhistas) (COCKELL; PERTICARRARI, 2005). Há ainda a necessidade de adequação das tarefas de uma determinada linha de produção para cumprir determinações das Normas Regulamentadoras (NRs), afetando às formas de desempenhar as tarefas nos postos de trabalho.

As NRs são definidas pela Associação Brasileira de Normas Técnicas (ABNT) e têm a força de lei, obrigando as empresas a se adequarem sob pena de passarem por um processo de imposição de multas e, até mesmo, interdições do posto de trabalho.

A NR-17 (BRASIL, 2009), que dispõe sobre Ergonomia, tem como objetivo fazer com que os postos de trabalho atendam aos fatores fisiológicos e psicológicos daqueles que irão desempenhar alguma atividade nesses locais proporcionando o máximo conforto, segurança e com desempenho eficiente (MÁSCULO; VIDAL, 2011). 


\subsection{A importância da compreensão do trabalho para fazer a sua transformação}

Guérin et al. (2001), comentam que a transformação do trabalho é o objetivo da ação ergonômica. Ainda segundo os autores, essa transformação deve contribuir para que as concepções das situações de trabalho não alterem a saúde dos operadores e, que os objetivos econômicos idealizados pela empresa sejam alcançados.

Abrahão (2002), comenta que em projetos de automação de um posto de trabalho, o uso da ergonomia traz grandes contribuições no processo de introdução dessa nova tecnologia. Para um projeto de automatização, algumas questões precisam ser levantadas e bem analisadas para que o projeto atenda, de fato, às necessidades do posto de trabalho: a escolha da melhor solução para determinada operação, contemplar todas as atividades que compreendem uma determinada tarefa, evitar que ao eliminar fatores de risco das atividades que se pretende transformar não surjam outras questões ergonômicas que não existiam no modelo anterior, definição do nível de automatismo que se pretende e como qualificar os trabalhadores que desempenharão essas novas atividades (ABRAHÃO, 2000).

Na maior parte dos casos de transformação do trabalho os aspectos financeiros, técnicos ou organizacionais, não são analisados sob o ponto de vista do homem fazendo parte do sistema de produção (GUÉRIN et al., 2001). Normalmente, o orçamento do investimento já está estabelecido, a tecnologia a ser usada já está definida, o grupo de projeto determina o fluxo de produção e estabelece o layout do espaço de trabalho (GUÉRIN et al., 2001).

A análise do trabalho é uma metodologia que aborda a análise da atividade, a análise dos fatores econômicos, técnicos e sociais, além dos efeitos do funcionamento da empresa sobre os trabalhadores envolvidos no processo (DANIELLOU; JACKSON FILHO, 2004).

Segundo Abrahão e Pinho (2002), a qualificação dos trabalhadores que desempenharão as tarefas nesse novo ambiente, remodelado, é outro aspecto que deve ser abordado. A inovação de um posto de trabalho traz a necessidade de qualificação técnica daqueles que terão a responsabilidade de lidar com essas novas tecnologias.

Essa qualificação não se restringe somente à equipe de Engenharia e Manutenção, mas, também, ao pessoal operacional. Estes sofrerão mais ainda com a implantação de um projeto de inovação, devido às alterações que ocorrerão nas suas tarefas após a implantação do projeto. As margens de manobra existentes com a operação manual serão, sem dúvida, reduzidas com o novo sistema (ABRAHÃO; PINHO, 2002).

Abrahão e Pinho (2002), mostram que as transformações relativas ao trabalho no mundo estão desencadeando um novo modelo nas relações econômicas, sociais e políticas. Essas transformações ocorrem devido a abertura de mercados e da evolução da tecnologia microeletrônica. Segundo os autores, essa evolução tecnológica está presente em toda a cadeia produtiva. Essas transformações estão causando impactos nas condições de trabalho, sobretudo nas competências dos trabalhadores diante dessa nova realidade. É importante destacar a qualificação técnica desses trabalhadores, a capacidade de diagnosticar e tomar uma decisão com relação a alguma situação (ABRAHÃO; PINHO, 2002). 
A pressão psicológica sofrida pelos trabalhadores, ao se depararem com uma nova forma de desempenhar a antiga tarefa, e a diminuição da margem de manobra que existia antes dessa alteração, são questões ergonômicas que precisariam ser discutidas durante um projeto de inovação tecnológica (ABRAHÃO, 2000).

Conforme Abrahão e Pinho (2002), há um amplo debate na comunidade científica sobre os efeitos da informática no homem. Segundo os autores, a Ergonomia faz uso dos conhecimentos científicos em áreas como a Antropometria, Fisiologia, Psicologia, Sociologia e os aplica nessas questões de alterações dos postos de trabalho. "Os critérios usados pela Ergonomia nessa avaliação são baseados em três itens: segurança, eficiência e bem-estar dos trabalhadores nessas novas situações de trabalho" (ABRAHÃO; PINHO, 2002, p. 47).

Segundo Abrahão e Pinho (2002), a intenção da Ergonomia é obter um equilíbrio entre os fatores mencionados acima para uma determinada atividade. Dessa forma, é preciso levar em consideração as características dos trabalhadores, os elementos do ambiente de trabalho e como eles são apresentados aos operadores e como estes os percebem. Como sujeito ativo do processo, dependendo da situação, ele transforma permanentemente a sua atividade para atender a uma nova necessidade.

E é a falta de análise desses fatores que pode fazer com que um projeto de inovação tenha falhas na sua implantação, provocando intervenções constantes para a correção das falhas do projeto. Duarte e Cordeiro (2000), destacam que imaginar que na etapa de montagem do sistema projetado seja apenas executar as decisões tomadas anteriormente é acreditar que tudo foi previsto e nesta etapa do processo precisaria, apenas, assegurar que os trabalhos de implantação da nova linha estejam em conformidade com as especificações do projeto. Mas, essa é uma visão limitada pois na etapa de execução muitas decisões ainda serão tomadas e precisarão do envolvimento de diferentes pessoas com diferentes saberes e especialidades (DUARTE; CORDEIRO, 2000). Béguin e Duarte (2008), comentam a importância das relações entre a atividade de trabalho e a novidade técnica. Não ocorrerão mudanças concretas no meio industrial sem que se analise a contribuição criativa que ocorre nas atividades de trabalho (BÉGUIN; DUARTE, 2008).

\section{PROCEDIMENTOS METODOLÓGICOS}

Esta pesquisa teve uma abordagem qualitativa, utilizando como método o estudo de caso. A aplicação do método de estudo de caso se justifica quando se analisa fenômenos sociais no contexto da vida real, na busca de explicações de como ou porque tal fenômeno ocorre, e quando se tem pouco controle sobre os eventos (YIN, 2010).

A pesquisa baseou-se em uma análise a posteriori de uma transformação produtiva (um projeto de automatização), na qual o pesquisador participou de forma ativa das etapas de projeto e implantação. Portanto, neste trabalho, o pesquisador teve a oportunidade de refletir o processo de construção técnica e social da solução adotada, bem como avaliar os impactos dessas melhorias. 
Para esta pesquisa foram utilizadas as seguintes fontes de evidências: análise de atas de reuniões, mensagens enviadas por e-mail entre os participantes do projeto, documentos de domínio público, como as decisões tomadas pelo Ministério Público, entrevistas com os atores do processo: os usuários do sistema nos dois contextos antes da automatização e após a automatização; o Engenheiro da empresa objeto do presente estudo que era o responsável pelo processo de concepção do projeto; e o Técnico de Segurança do Trabalho da empresa, observação direta e participante.

Com os dados levantados foi possível elaborar um amplo diagnóstico relacionando as situações encontradas com os conceitos fundamentais da Ergonomia. Com isso, foi possível desenvolver uma discussão entre os resultados obtidos após a implantação do projeto de melhoria que teve como abordagem o modelo tradicional de desenvolvimento de projetos de engenharia.

\section{RESULTADOS}

O caso escolhido para o estudo foi um projeto de automatização implantado em uma empresa do seguimento de embalagens de polpa moldada para ovos e frutas, no setor de acabamento de bandejas para o acondicionamento e transporte de maçã, que tinha como objetivo substituir as atividades manuais, que existiam nesse setor, através da implantação de dispositivos eletromecânicos acionados através de sensores. A Figura 2 ilustra o layout original do posto de trabalho escolhido para esta pesquisa onde as operações em cada seção e o transporte dos produtos eram desenvolvidos manualmente.

Figura 2 - Layout original.

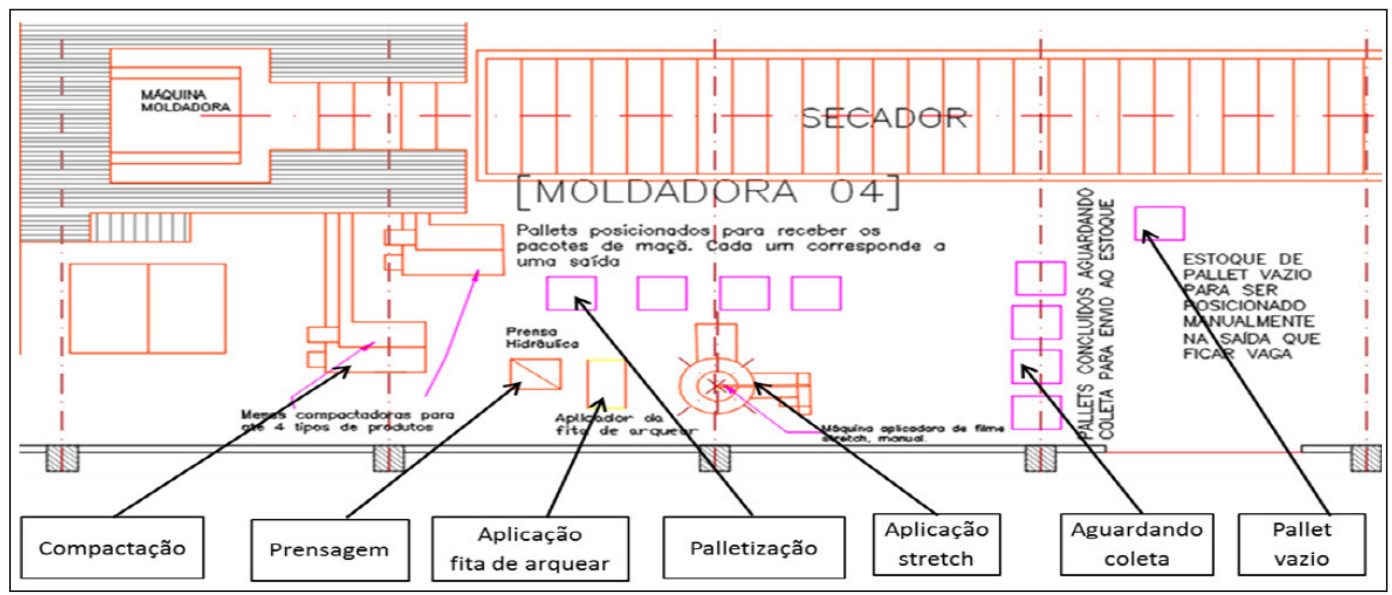

Fonte: Elaboração dos autores. 
A demanda desse projeto estava relacionada aos diversos casos de afastamento devido às Lesões por Esforços Repetitivos (LER) e por Distúrbios Osteomusculares Relacionados ao Trabalho (DORT).

Com o objetivo de eliminar os referidos casos de afastamentos por doenças ocupacionais foi concebido, então, um projeto de automatização da linha de acabamento da produção de bandejas de maçã. O projeto foi desenvolvido seguindo uma abordagem tradicional de projeto de engenharia (top-down ou descendente), na qual os problemas técnicos foram definidos a priori e somente em etapas posteriores foram consideradas as necessidades dos usuários (DUARTE, 2002). A Figura 3 ilustra o layout proposto com a automatização das operações.

Figura 3 - Layout proposto com a automatização.

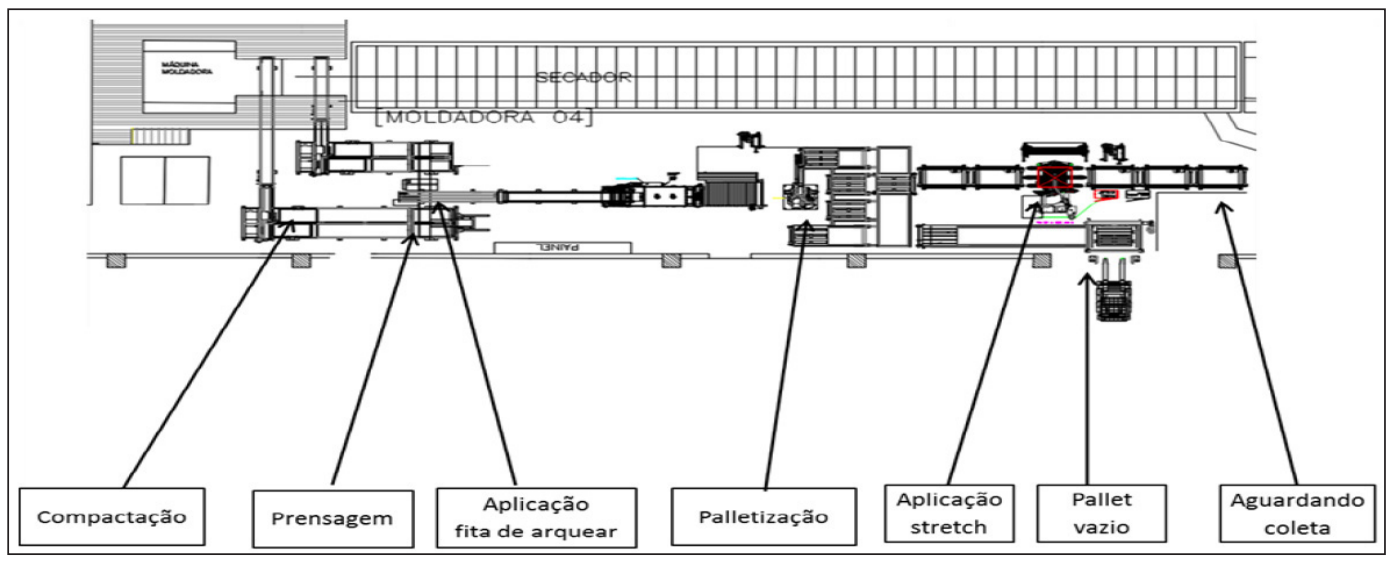

Fonte: Elaboração dos autores.

O Quadro 1 compara o processo original e a alteração proposta das atividades desenvolvidas na operação de acondicionamento das bandejas de maçã. 
Quadro 1 - Comparação entre o processo original e a alteração proposta.

\begin{tabular}{|c|c|c|}
\hline OPERAÇÕES & SITUAÇÃO ANTES DA AUTOMAÇÃO & PROJETO DE MELHORIA \\
\hline $\begin{array}{l}\text { Contagem e } \\
\text { compactação das } \\
\text { bandejas }\end{array}$ & $\begin{array}{l}\text { Contagem feita por sensor de presença (aplicação } \\
\text { de spray de água na última bandeja do lote). } \\
\text { Compactação: feita manualmente. }\end{array}$ & $\begin{array}{l}\text { Sensor de presença para contagem } \\
\text { e sistema servo-motor para } \\
\text { compactação. }\end{array}$ \\
\hline $\begin{array}{l}\text { Transporte do } \\
\text { pacote para a } \\
\text { prensagem }\end{array}$ & $\begin{array}{l}\text { O Ajudante de Produção transportava o pacote para } \\
\text { posicioná-lo na prensa fazendo duas viagens, devido } \\
\text { ao volume a ser movimentado. }\end{array}$ & $\begin{array}{l}\text { Sistema servo-motor arrasta o } \\
\text { pacote até área de prensagem. }\end{array}$ \\
\hline $\begin{array}{l}\text { Operação de } \\
\text { prensagem }\end{array}$ & $\begin{array}{l}\text { Com o pacote posicionado na prensa o Ajudante de } \\
\text { Produção acionava o comando da prensa. }\end{array}$ & $\begin{array}{l}\text { Parafuso sem fim faz a prensagem } \\
\text { do pacote. }\end{array}$ \\
\hline $\begin{array}{l}\text { Transporte para a } \\
\text { aplicação da fita de } \\
\text { arquear }\end{array}$ & $\begin{array}{l}\text { O pacote prensado era retirado da prensa e } \\
\text { transportado pelo Ajudante de Produção até a } \\
\text { máquina aplicadora da fita de arquear. }\end{array}$ & $\begin{array}{l}\text { Braço mecânico faz as } \\
\text { movimentações do pacote após a } \\
\text { prensagem. }\end{array}$ \\
\hline $\begin{array}{l}\text { Aplicação da fita de } \\
\text { arquear }\end{array}$ & $\begin{array}{l}\text { o Ajudante de Produção posicionava o pacote na } \\
\text { máquina, acionava o comando para a aplicação da fita } \\
\text { em uma extremidade e repetia o processo na outra. }\end{array}$ & $\begin{array}{l}\text { Um controlador lógico programável } \\
\text { (PLC) aciona a aplicadora de fita. }\end{array}$ \\
\hline $\begin{array}{l}\text { Transporte para a } \\
\text { paletização }\end{array}$ & $\begin{array}{l}\text { O Ajudante de Produção retirava o pacote da máquina } \\
\text { e o levava até a área onde estavam os pallets. }\end{array}$ & $\begin{array}{l}\text { Braço mecânico posiciona o pacote } \\
\text { para a área do robô. }\end{array}$ \\
\hline $\begin{array}{l}\text { Paletização } \\
\text { dos produtos } \\
\text { prensados }\end{array}$ & $\begin{array}{l}\text { O Ajudante de Produção posicionava os } 24 \text { pacotes no } \\
\text { pallet correspondente. }\end{array}$ & $\begin{array}{l}\text { Feita automaticamente por um } \\
\text { robô. }\end{array}$ \\
\hline $\begin{array}{l}\text { Transporte para a } \\
\text { aplicação do stretch }\end{array}$ & $\begin{array}{l}\text { O Ajudante de Produção levava o conjunto para a } \\
\text { máquina aplicadora do filme stretch. }\end{array}$ & $\begin{array}{l}\text { Movimentação feita por esteiras } \\
\text { comandadas pelo PLC. }\end{array}$ \\
\hline $\begin{array}{l}\text { Aplicação do filme } \\
\text { stretch }\end{array}$ & $\begin{array}{l}\text { O Ajudante de Produção amarrava a ponta do filme } \\
\text { stretch na base do pallet e acionava o comando. }\end{array}$ & $\begin{array}{l}\text { Sensor de presença envia sinal para } \\
\text { o PLC iniciar. }\end{array}$ \\
\hline $\begin{array}{l}\text { Aplicação da } \\
\text { etiqueta }\end{array}$ & $\begin{array}{l}\text { O Ajudante de Produção recebia as etiquetas de } \\
\text { identificação e as colava manualmente. }\end{array}$ & $\begin{array}{l}\text { Impressora emite a etiqueta e a } \\
\text { aplica no pallet. }\end{array}$ \\
\hline $\begin{array}{l}\text { Transporte para } \\
\text { expedição do pallet }\end{array}$ & $\begin{array}{l}\text { O Ajudante de Produção levava o pallet concluído até } \\
\text { o setor de coleta, com transportador manual. }\end{array}$ & O PLC comanda as esteiras. \\
\hline
\end{tabular}

Fonte: Elaboração dos autores.

A partir da entrega do novo sistema e com todos os testes concluídos, a linha de produção de bandejas de maçã entrou em regime normal de operação e junto com o início da produção surgiram outros problemas. 
O Quadro 2 resume as situações observadas durante as análises realizadas com a linha em regime normal de produção.

Quadro 2 - Análise das situações de trabalho após implantação do projeto de automação.

\begin{tabular}{|c|c|c|}
\hline OPERAÇÕES & SOLUÇÃO ADOTADA & CONSTRANGIMENTOS \\
\hline $\begin{array}{l}\text { Contagem e } \\
\text { compactação } \\
\text { das bandejas } \\
\text { após processo de } \\
\text { secagem }\end{array}$ & $\begin{array}{l}\text { O sistema conta os produtos que passam pela esteira, } \\
\text { empilha e separa os pacotes concluídos através do } \\
\text { acionamento de um batedor comandado por um } \\
\text { servo-motor. }\end{array}$ & $\begin{array}{l}\text { Há a necessidade eventual de } \\
\text { intervenção manual para a correção } \\
\text { da posição de alguma bandeja que } \\
\text { tenha virado durante o transporte. }\end{array}$ \\
\hline $\begin{array}{l}\text { Transporte } \\
\text { do conjunto } \\
\text { de bandejas } \\
\text { compactadas para } \\
\text { a prensagem }\end{array}$ & $\begin{array}{l}0 \text { pacote é transportado até a mesa de prensagem } \\
\text { por um arrastador comandado por um servo motor e } \\
\text { correia dentada. }\end{array}$ & $\begin{array}{l}\text { Necessário acessar tanto a área de } \\
\text { prensagem como a área inferior da } \\
\text { mesa de compactação para retirar } \\
\text { alguma bandeja que tenha ficado } \\
\text { mal posicionada, vindo a travar o } \\
\text { transportador. }\end{array}$ \\
\hline $\begin{array}{l}\text { Operação de } \\
\text { prensagem }\end{array}$ & $\begin{array}{l}\text { Com o pacote posicionado na mesa de prensagem, } \\
\text { um parafuso sem fim é acionado através de sensores, } \\
\text { fazendo movimentar as placas de prensagem } \\
\text { (martelos). }\end{array}$ & $\begin{array}{l}\text { São raras as ocorrências, mas pode } \\
\text { ser preciso retirar o pacote dessa } \\
\text { área caso haja alguma falha na } \\
\text { prensagem do pacote. }\end{array}$ \\
\hline $\begin{array}{l}\text { Operação da } \\
\text { aplicação da fita de } \\
\text { arquear nas duas } \\
\text { extremidades do } \\
\text { pacote }\end{array}$ & $\begin{array}{l}\text { O mesmo braço mecânico posiciona o pacote na } \\
\text { máquina aplicadora de fita de arquear, a aplicação e } \\
\text { a solda da fita são feitas automaticamente nas duas } \\
\text { extremidades do pacote. }\end{array}$ & $\begin{array}{l}\text { A substituição do carretel de fita de } \\
\text { arquear é feita manualmente. } \\
\text { Quando o sistema de aplicação } \\
\text { da fita falha, há a necessidade de } \\
\text { acessar o dispositivo mecânico da } \\
\text { aplicadora de fita de arquear. }\end{array}$ \\
\hline $\begin{array}{l}\text { Operação da } \\
\text { aplicadora do filme } \\
\text { stretch }\end{array}$ & $\begin{array}{l}\text { Ao chegar no ponto de aplicação do filme stretch um } \\
\text { sensor comanda o sistema para iniciar o processo. }\end{array}$ & $\begin{array}{l}\text { A substituição do rolo de filme } \\
\text { stretch é feita manualmente, com } \\
\text { risco de lesões nos ombros e na } \\
\text { coluna. }\end{array}$ \\
\hline $\begin{array}{l}\text { Alimentação de } \\
\text { pallet vazio }\end{array}$ & $\begin{array}{l}\text { O alimentador de pallet é abastecido pelo Operador } \\
\text { de Empilhadeira. } \\
\text { Quando um pallet é concluído e deixa a área do robô, } \\
\text { um novo pallet é liberado pelo alimentador e uma } \\
\text { esteira transportadora leva esse novo pallet para a } \\
\text { área correspondente. }\end{array}$ & $\begin{array}{l}\text { O Operador de Empilhadeira } \\
\text { precisa fazer várias manobras. } \\
0 \text { alimentador só pode ser } \\
\text { abastecido quando estiver sem } \\
\text { pallet no seu suporte. } \\
\text { Não pode ser colocado mais do que } \\
10 \text { pallets em cada intervenção. } \\
\text { Necessidade de intervenção } \\
\text { do Ajudante de Produção para } \\
\text { desobstruir o alimentador. }\end{array}$ \\
\hline
\end{tabular}

Fonte: Elaboração dos autores. 


\section{DISCUSSÕES}

A finalidade desta pesquisa era evidenciar como o uso da Ergonomia em projetos de concepção poderia contribuir para a redução do aparecimento de novos constrangimentos após a implantação de um novo layout.

Após a implantação do projeto esperava-se que as alterações efetuadas na linha proporcionassem aos trabalhadores maior tempo livre, de tal forma que pudessem se dedicar mais nas inspeções da qualidade do produto, além da possibilidade de se reduzir o número de postos de trabalho. O que se verificou, no entanto, após a implantação do projeto, foi a ocorrência de problemas não previstos durante a sua concepção.

Daniellou (2007), comenta que outras categorias profissionais estão envolvidas na expressão dos objetivos do projeto. São os atores da concepção e que não estão limitados somente aos projetistas profissionais (DANIELLOU, 2007). O autor comenta, ainda, que normalmente os engenheiros criam os dispositivos técnicos e determinam os procedimentos de utilização correspondentes e se supõe que o trabalho futuro seja um reflexo fiel das tarefas definidas nesses procedimentos. Comenta, ainda, que investimentos industriais importantes acabam tendo um início complicado com perdas de produção, falta da qualidade esperada, incidentes, acidentes, etc. Essas dificuldades são causadas, essencialmente, por dois fatores: a gestão do projeto, pautada no papel dos atores e estruturação das etapas e a falta de reflexão sobre o trabalho futuro ao longo do processo de concepção (DANIELLOU, 2002).

Fontes et al. (2008), comentam que os trabalhadores são constantemente submetidos a variações na operação que normalmente não são consideradas pela empresa e isso acarreta um volume grande de procedimentos não formais, na sua rotina diária, gerados pelas manobras que os trabalhadores utilizam para superar essas variabilidades. Durante o processo de observação do sistema de automatização implantado verificou-se que há momentos em que o Ajudante de Produção precisava intervir em alguns dispositivos para evitar paralisações da operação, devido a alguma obstrução ou má formação do produto. Como essas variabilidades do processo não foram contempladas pelo projeto, o Ajudante de Produção é obrigado a fazer algumas adaptações diante dessas ocorrências. Broberg (2008), mostra em seu estudo que através do uso de métodos participativos é possível promover uma aproximação maior entre os engenheiros do projeto e os usuários e, com isso, surgem propostas de alterações em layouts, elaboração de novos procedimentos de trabalho relacionados à saúde, postura e ao ambiente de trabalho.

Fontes et al. (2008), comentam que através da Análise Ergonômica do Trabalho, e das características evidenciadas pelos discursos dos trabalhadores, facilitam a identificação dos constrangimentos existentes no espaço de trabalho. Com isso é possível desenvolver soluções para esses espaços de trabalho com a finalidade de reduzir esses constrangimentos, trazendo à tona aspectos físicos e materiais ligados aos operadores. As soluções baseadas no contexto da Ergonomia garantem eficiência nas soluções implantadas, pois criam espaços de negociação entre os atores envolvidos no processo (FONTES et al., 2008). 


\section{CONCLUSÕES}

A aplicação dos conceitos da Ergonomia com foco na atividade pode promover um conflito positivo entre os diversos atores envolvidos no processo de desenvolvimento do projeto. $\mathrm{E}$ essa discussão contribui para que a abordagem ascendente também seja aplicada no processo, complementado a abordagem tradicionalmente utilizada nos projetos de engenharia.

Este estudo teve como foco o resultado da implantação de um projeto de concepção de espaço de trabalho. Mais precisamente, um projeto que visava a melhoria das condições de trabalho de uma linha de produção de embalagens de polpa moldada para maçã. Nesse contexto, buscou-se compreender as razões que levaram um projeto que, ao mesmo tempo, eliminou os problemas ergonômicos que a antiga linha possuía, e gerou outros tipos de constrangimentos, que essa mesma linha não possuía.

\section{CONSIDERAÇÕES ACERCA DOS OBJETIVOS DA PESQUISA}

O objetivo desta pesquisa, de entender como a Ergonomia poderia contribuir para que um projeto de concepção de espaço de trabalho seja mais satisfatório, foi atingido, uma vez que pôde-se evidenciar que a falta da análise da atividade e o não envolvimento de todos os atores envolvidos no processo, levou os projetistas a considerarem a operação somente baseada no trabalho prescrito.

Outra evidência constatada foi a não avaliação da atividade futura. Ação que poderia ter sido executada através de simulações com o uso de dispositivos simples como um jogo de tabuleiro com maquetes representando os equipamentos, marcações no piso da área onde o sistema seria montado, etc. Essa avaliação contribuiria para verificação das condições de circulação e acesso dos trabalhadores aos diversos sistemas implementados, antecipando problemas futuros.

Esta pesquisa está limitada a um único estudo de caso, o que impossibilita a generalização das conclusões efetuadas. Acredita-se, porém, que as considerações levantadas nesta pesquisa incentivem os profissionais envolvidos nos projetos de concepção de espaço de trabalho a utilizar os conceitos da Ergonomia no desenvolvimento desses projetos.

\section{REFERÊNCIAS}

ABRAHÃO, J. I. Reestruturação produtiva e variabilidade: uma abordagem de ergonomia. Psicologia: teoria e pesquisa, p. 49-54, 2000.

ABRAHÃO, J. I.; PINHO, D. L. As transformações do trabalho e desafios teórico-metodológicos da ergonomia. Estudos de Psicologia, p. 45-52, 2002.

BÉGUIN, P.; DUARTE, F. A inovação: entre o trabalho dos projetistas e o trabalho dos operadores. Laboreal, Porto, 2008. 
BRAATZ, D. Suportes de simulação como objetos intermediários para incorporação da perspectiva da atividade na concepção de situações produtivas. 2015. $246 \mathrm{f}$. Tese (Doutorado) - Engenharia de Produção, Universidade Federal de São Carlos, São Carlos, São Paulo, 2015.

BRAATZ, D.; MENEGON, N. L.; FONTES, A. R. M.; TONIN, L. A. Simulação humana digital na concepção de postos de trabalho: estudo comparativo de casos. Gestão \& Produção, v. 19, n. 1, p. 79-92, 2012.

BRASIL. Ministério do Trabalho. Normas regulamentadoras em segurança e medicina do trabalho. São Paulo: Atlas, 2009.

BROBERG, O. Quando o projeto participativo de espaços de trabalho se encontra com o projeto de engenharia em eventos de colaboração mútua. Laboreal, Porto, n. 4, p. 47-58, 2008.

COCKELL, F. F.; PERTICARRARI, D. O papel dos atores sociais na validação da ação ergonômica e na construção dos espaços de negociação. Revista da ABET, v. 5, n. 1, 2005.

DANIELLOU, F. Métodos em ergonomia de concepção: A análise de situações de referência e a simulação do trabalho. In: DUARTE, F. (Org.). Ergonomia e projeto na indústria de processo contínuo. Rio de Janeiro: Lucerna, 2002

DANIELLOU, F. A ergonomia em busca de seus princípios: debates epistemológicos. São Paulo: Blücher, 2004.

DANIELLOU, F. A ergonomia na condução de projetos de concepção de sistemas de trabalho. In: FALZON, P. (Ed.). Ergonomia. São Paulo: Edgard Blücher, 2007.

DANIELLOU, F.; JACKSON FILHO, J. M. Questões apistemológicas levantadas pela ergonomia de projeto. In: DANIELLOU, F. (Coord.). A ergonomia em busca de seus princípios: debates epistemológicos. São Paulo: Edgard Blücher, 2004.

DUARTE, F. D.; CORDEIRO, C. C. A etapa de execução da obra: um momento de decisões. Produção, v. 9, n. SPE, p. 5-27, 2000.

DUARTE, F. et al. Ergonomia e projetos industriais: estudo de caso em uma indústria de processo químico. Rio de Janeiro: PEP/COPPE/UFRJ, 1999.

FALZON, P. Ergonomia. São Paulo: Blücher, 2007.

FONTES, A. R. Ergonomia e design no projeto de espaço de trabalho: o balcão de atendimento dos Correios. 2011. 256 f. Tese (Doutorado em Engenharia de Produção) - Universidade Federal de São Carlos, São Carlos, 2011.

FONTES, A. R.; MENEGON, F. A.; RODRIGUES, D. S. Process of ergonomic intervention in an oil refinery: typification of solutions in the context of ergonomics. In: SYMPOSIUM HUMAN FACTORS IN ORGANIZATIONAL DESIGN AND MANAGEMENT, 9, 2008, Guarujá. Anais... São Paulo: Edgard Blücher, 2008. 
GUÉRIN, F. Compreender o trabalho para transformá-lo: a prática da ergonomia. São Paulo: Edgard Blücher, 2001.

INTERNATIONAL ERGONOMICS ASSOCIATION. Disponível em: <http://www.iea.cc/ ergonomics/>. Acesso em: 15 jul. 2015.

LIMA, F. D. Ergonomia e projeto organizacional: a perspectiva do trabalho. Produção, v. 9, n. SPE, p. 71-98, 2000.

LIMA, F. D.; RESENDE, A. E.; VASCONCELOS, R. C. Condicionantes sociais do projeto de instrumentos de trabalho: o caso de uma bancada de inspeção. Produção, v. 19, n. 3, p. 529544, 2009.

LIMA, F.; DUARTE, F. Integrando a ergonomia ao projeto de engenharia: Especificações ergonômicas e configurações de uso. Gestão e Produção, v. 21, n. 4, p. 679-690, 2014.

MÁSCULO, F. S.; VIDAL, M. C. Ergonomia: trabalho adequado e eficiente. Rio de Janeiro: Elsevier/ABEPRO, 2011.

MENEGON, N. L. Projeto de trabalho e projeto de engenharia: uma aproximação entre teoria do design e ergonomia. In: ENCONTRO NACIONAL DE ENGENHARIA DE PRODUÇÃO, 19, 1999, Rio de Janeiro. Anais... Rio de Janeiro: ENEGEP, 1999.

MORGAN, G. Imagens da organização. São Paulo: Atlas, 2006.

RODRIGUES, D. D. Integração entre ergonomia e projeto: o trabalho do operador de descoqueamento em uma refinaria de petróleo. 2012. $121 \mathrm{f}$. Dissertação (Mestrado) - Engenharia de Produção, Universidade Federal de São Carlos, São Carlos, São Paulo, 2012.

ROLDÃO, V. S. Gestão de projetos: uma perspectiva integrada. São Carlos: EdUFSCar, 2004.

ROZENFELD, H.; FORCELLINI, F. A.; AMARAL, D. C. Gestão de desenvolvimento de produtos: uma referência para a melhoria do processo. São Paulo: Saraiva, 2006.

SLACK, N.; CHAMBERS, S.; JOHNSTON, R. Administração da produção. São Paulo: Atlas, 2009.

TOLEDO, J. C.; SILVA, S.L.; MENDES, G.H.S.; JUGEND, D. Fatores críticos de sucesso no gerenciamento de projetos de desenvolvimento de produto em empresas de base tecnológica de pequeno e médio porte. Gestão E Produção, v. 15, n. 1, p. 117-134, 2008.

WISNER, A. Questões epistemológicas em ergonomia e em análise do trabalho. In: DANIELLOU, F. (Coord.). A ergonomia em busca de seus princípios: debates epistemológicos. São Paulo: Edgard Blücher, 2004.

YIN, R. K. Estudo de caso: planejamento e métodos. Porto Alegre: Bookman, 2010. 